\title{
Egoistic and Sociotropic Policy Preferences
}

\author{
Roman Liesch Michael M. Bechtel
}

Inequality and Fairness of Political Reforms

8-9 December 2016

University of Mannheim 


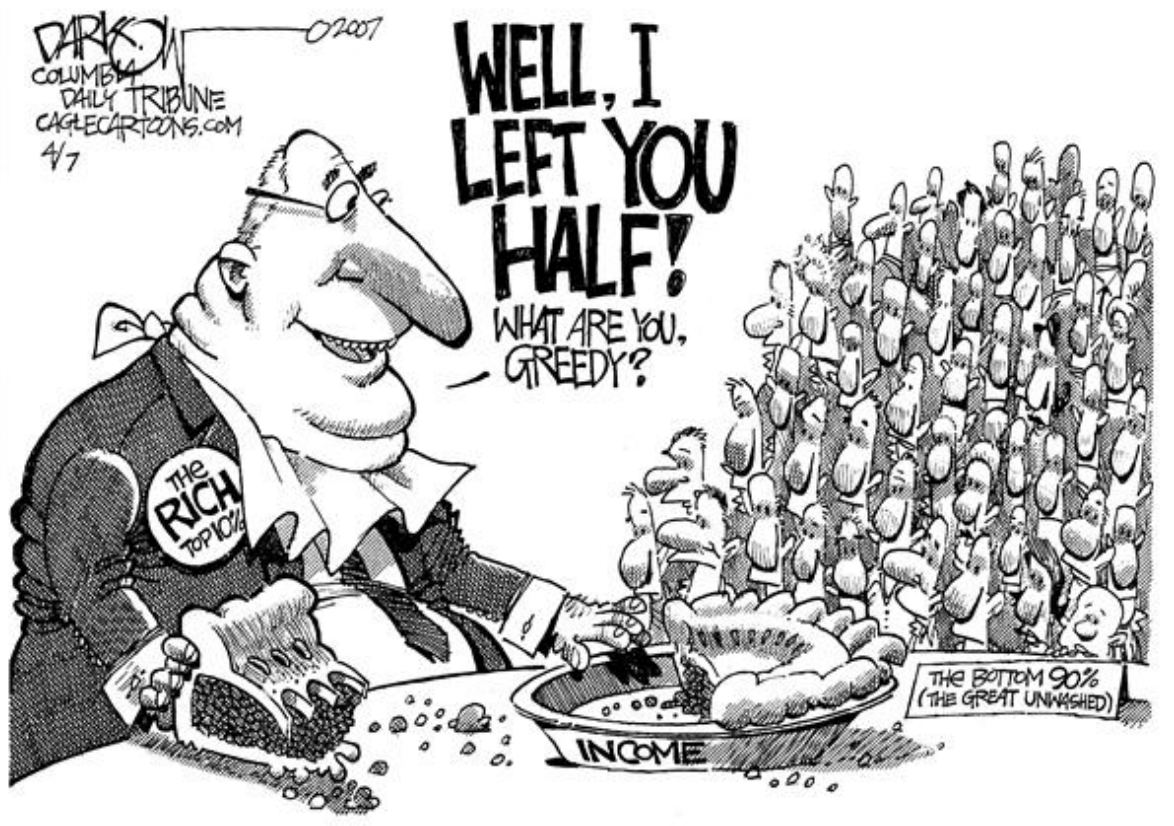




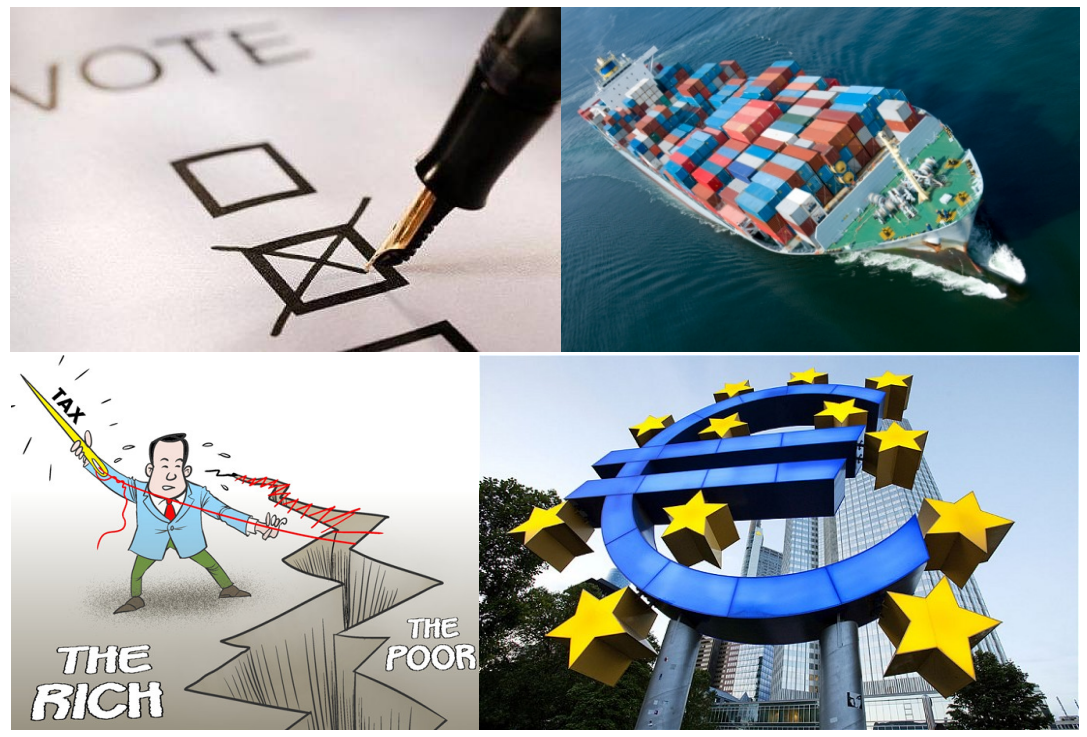




\section{We explore the sources of egoistic and sociotropic policy preferences.}

- Relative importance of self-interest and sociotropic concerns

- Empirical equivalence problem

- Novel income conjoint experiment to

(1) ... specify a policy's multidimensional income effects on self, average, and different income groups

(2) ... explore role of social comparisons and altruistic concerns

- Findings:

- $2: 1$

- Sensitivity to average income effects related to concern for the poorest.

- Similar sensitivities across various groups (including partisanship) 


\section{Individuals are motivated by personal gains...}

- Utility as a function of income

- Income guarantees living standard

- Preparation for adverse events (risk)

\section{Hypothesis 1 (Personal Income Effect)}

Personal income gains increase support for policy. 


\section{... but also by pro-social considerations.}

- Altruistic behavior generates satisfaction

- Concern for poorest: Improve situation of those who are worst off

\section{Hypothesis 2 (National/Average Income Effects)}

Average income gains increase support for policy. 


\section{Social benchmarking affects assessments of the income effects of policy.}

- Assessment of changes in income relative to a benchmark

- Own losses when others benefits may trigger envy

\section{Hypothesis 3 (Personal Income Gains: Social Comparison and Envy)}

Individuals are more opposed to income losses if others gain. 


\section{We implement a randomized conjoint experiment detailing the income effects of a policy.}

\section{Policy Dimensions and Values}

\begin{tabular}{l|l}
\hline Dimension & Values \\
\hline Changes in Incomes & \\
\hline $\begin{array}{l}\text { Average income in the United States } \\
\text { Average income in your sector of employment } \\
\text { Your personal income }\end{array}$ & $-\$ 5,000-\$ 2,000, \$ 0,+\$ 2,000,+\$ 5,000$ \\
\hline Changes of Wages in Different Income Categories & \\
\hline $\begin{array}{l}\text { Individuals that earn about } \$ 10 \mathrm{k} \text { a year } \\
\text { Individuals that earn about } \$ 85 \mathrm{k} \text { a year } \\
\text { Individuals that earn about } \$ 375 \mathrm{k} \text { a year }\end{array}$ & $-\$ 5,000-\$ 2,000, \$ 0,+\$ 2,000,+\$ 5,000$ \\
\hline
\end{tabular}

Note: The table shows the dimensions and corresponding values used in the conjoint experiment. 


\section{Survey respondents chose the policy reform they preferred based on the income effects.}

Please carefully review the options detailed below, then please answer the questions. Which policy do you prefer? (1/4)

\begin{tabular}{|c|c|c|}
\hline Impact of Policy on Incomes & Policy 1 & Policy 2 \\
\hline Individuals earning about $\$ 375,000$ per year & $\$ 0$ & $\$ 0$ \\
\hline Your personal income & $+\$ 5,000$ & $+\$ 5,000$ \\
\hline Average income in the United States & $+\$ 2,500$ & $+\$ 2,500$ \\
\hline Individuals earning about $\$ 85,000$ per year & $-\$ 5,000$ & $+\$ 2,500$ \\
\hline Individuals earning about $\$ 10,000$ per year & $+\$ 5,000$ & $+\$ 2,500$ \\
\hline Average income in your sector of employment & $+\$ 5,000$ & $-\$ 2,500$ \\
\hline YOUR CHOICE: & 0 & 0 \\
\hline
\end{tabular}




\section{We fielded an online survey among US citizens.}

- September/October 2016

- $\mathrm{N}=2,760$

- Each respondent rates 8 policies in four binary comparisons $(2 \times 4 \times 2,760=22,080$ evaluated policies $)$

- Quasi-behavioral measures of altruism and reciprocity

- Large number of additional covariates (income, age, gender, partisanship,...) 


\section{Individuals care about personal and national-level income changes.}

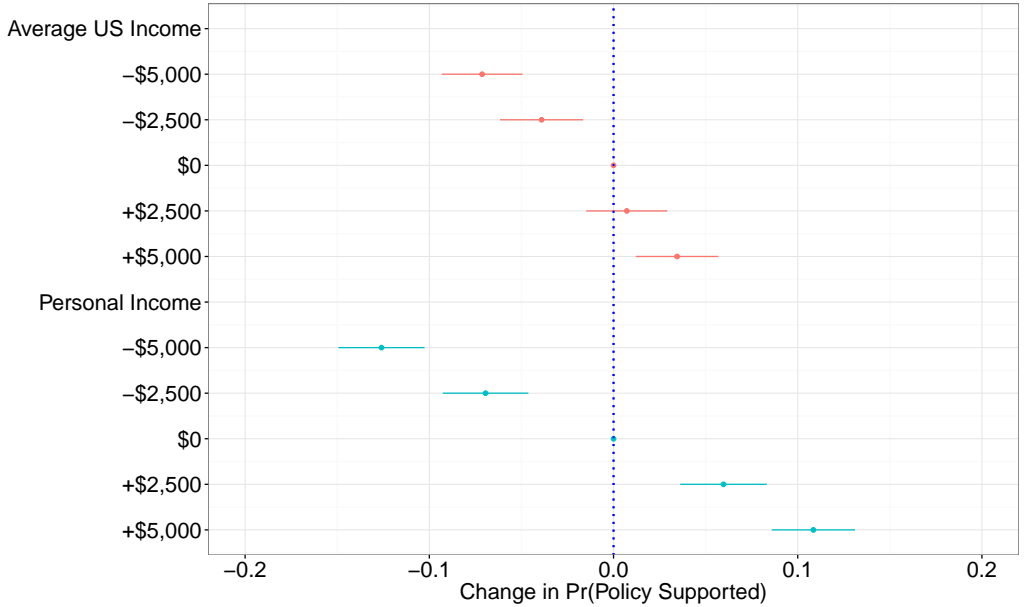




\section{Even those who gain personally are still averse to average income losses.}

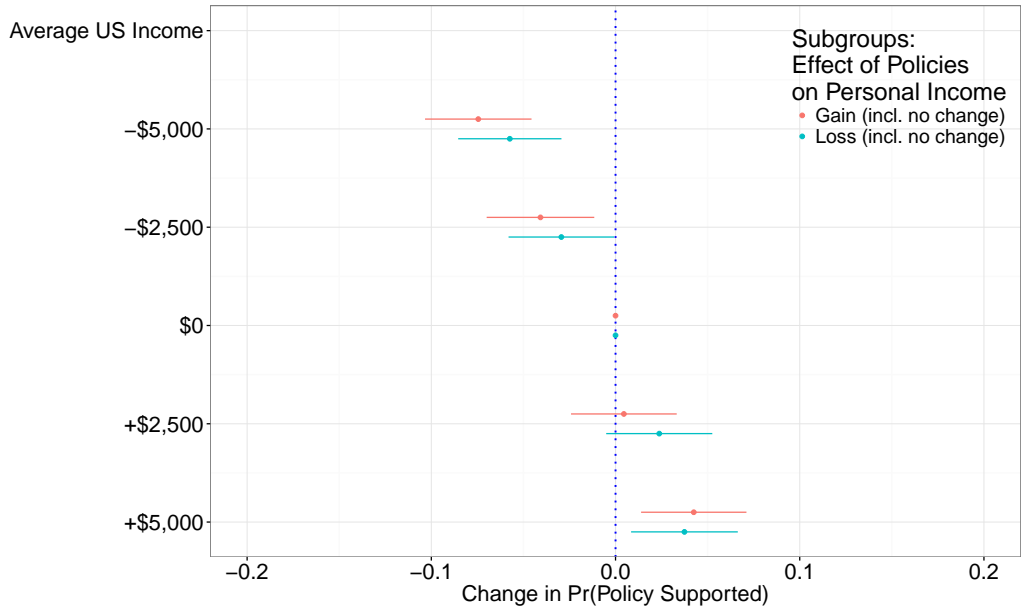




\section{Individuals care about the economic situation of the poor.}

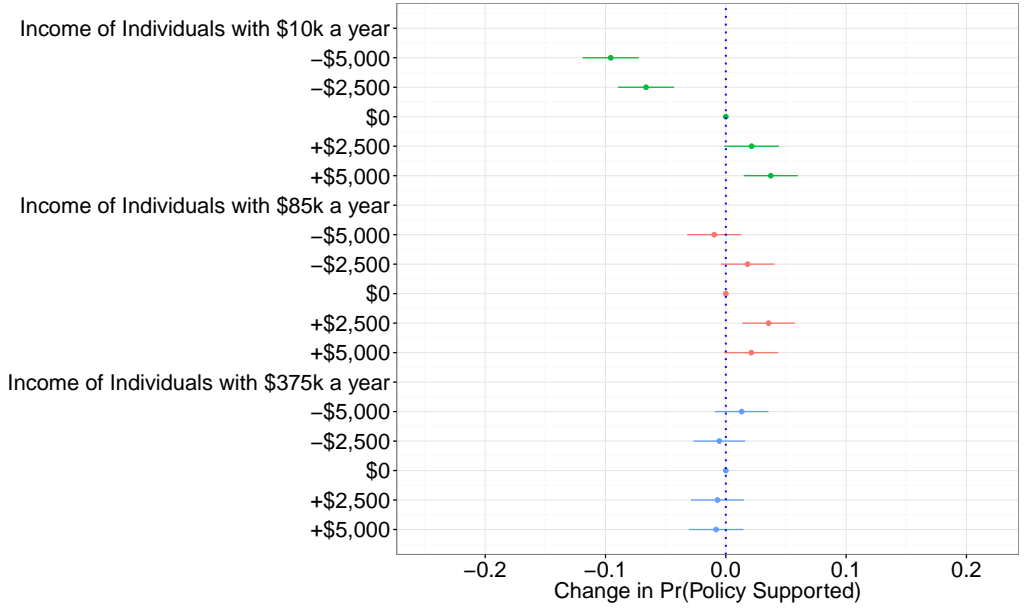




\section{Those with low and those with high incomes care about the poorest.}

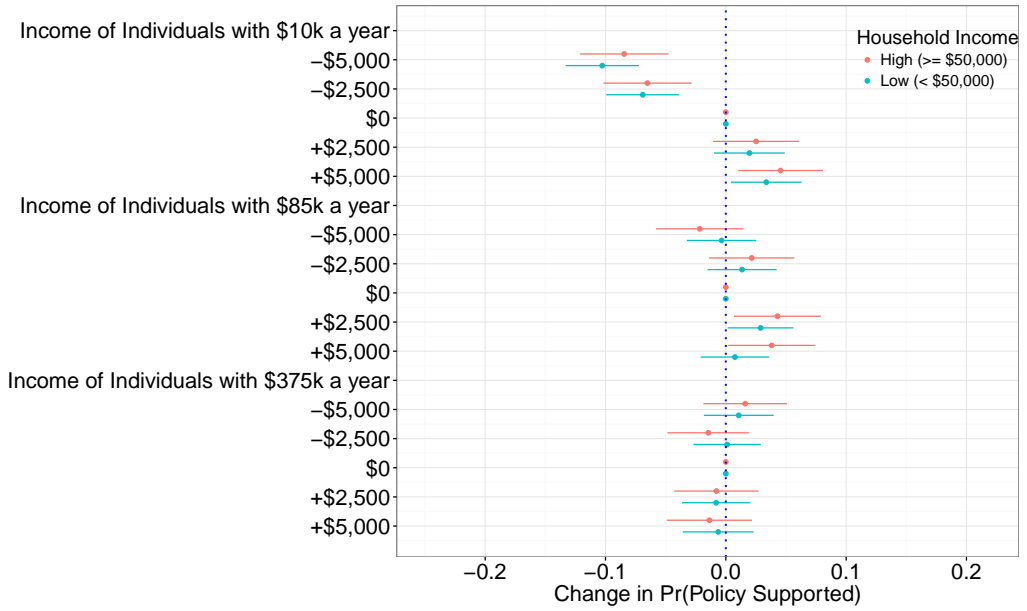




\section{Social benchmarking: How policies affect the poorest does not change personal income effects.}

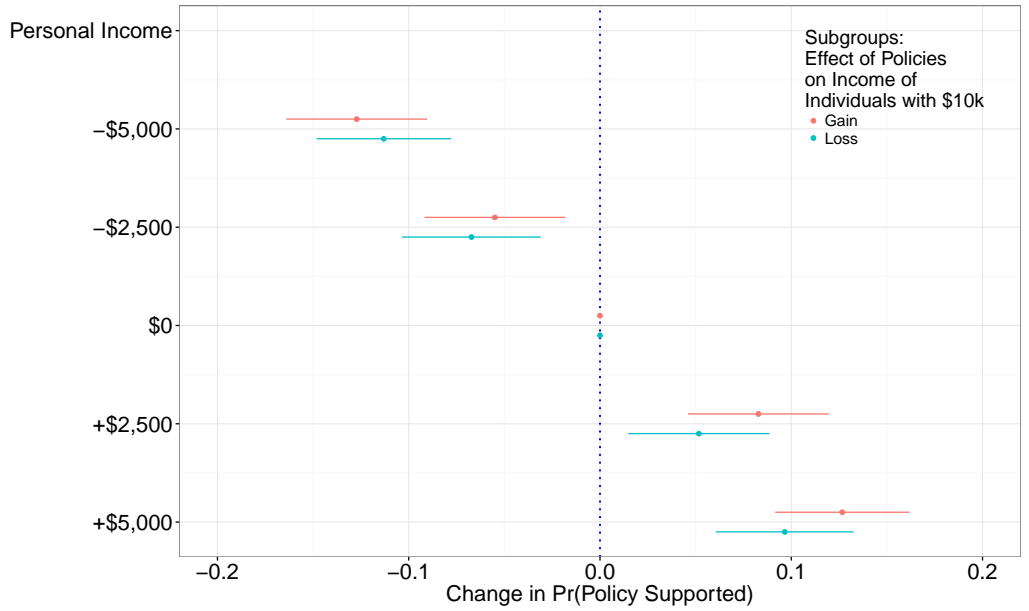




\section{Covariates help us to analyze differences in sensitivities between different groups.}

- Republicans and Democrats react similarly to income changes

- Identification with nationality does not influence sensitivities to income effects at the national level

- Social norms explain part of the sensitivity to national income increases

- Using relative income changes yields very similar results 


\section{We find that}

- Policy preferences have egoistic as well as sociotropic roots

- Personal income effects twice the size of national income effects

- Individuals concerned about welfare of the poorest

- Even if policy provides personal gains: Oppose income losses for the poor

- Remaining questions:

- Which role do attitudes towards redistribution play?

- Which role do fairness principles play (e.g., inequality aversion)? 


\section{Back up slides}




\section{Individuals care about average and personal income changes as well as low earners.}

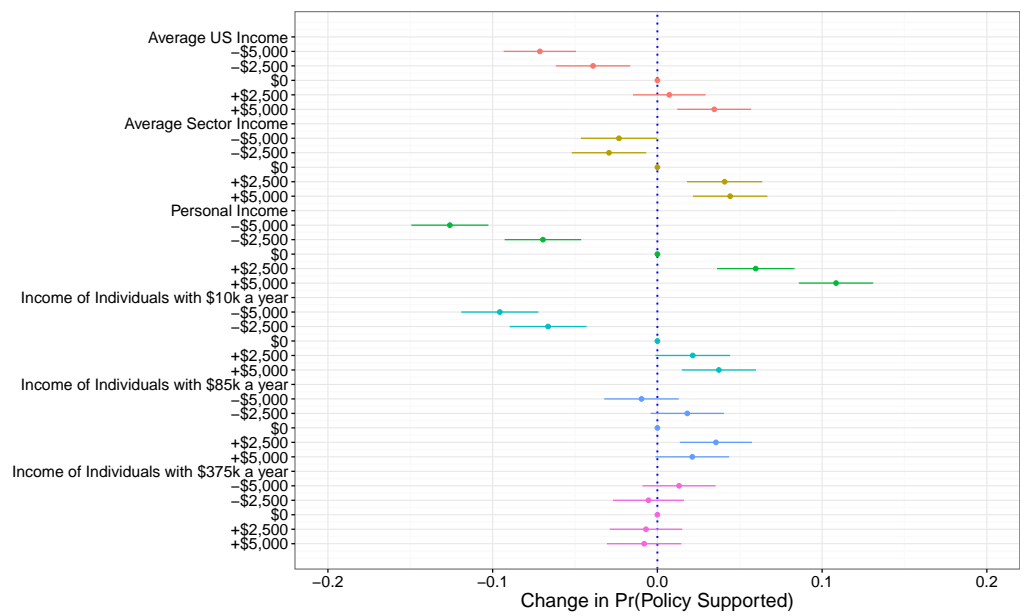




\section{How policies affect the income of the middle class and rich does not influence personal income effects.}
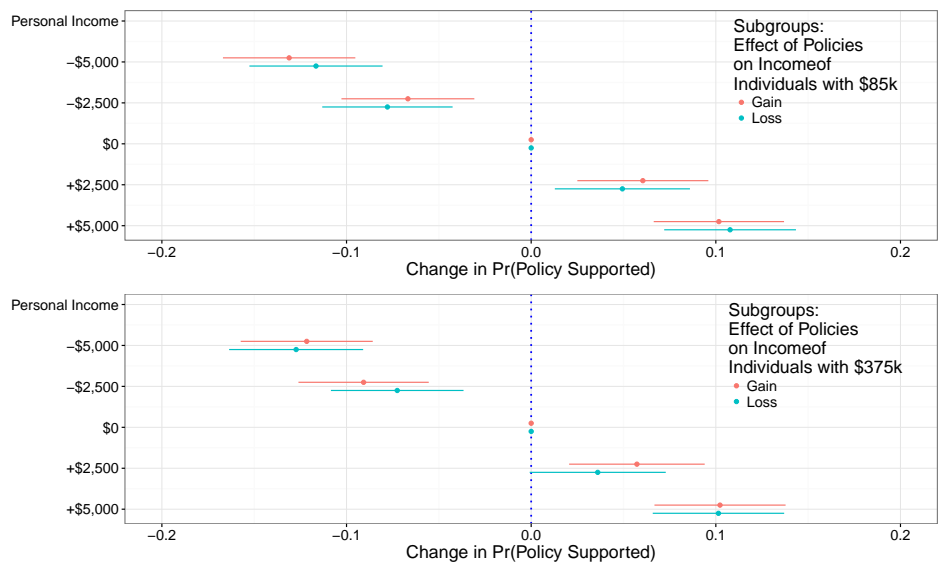


\section{National Identity does not influence support for policies that affect the country}

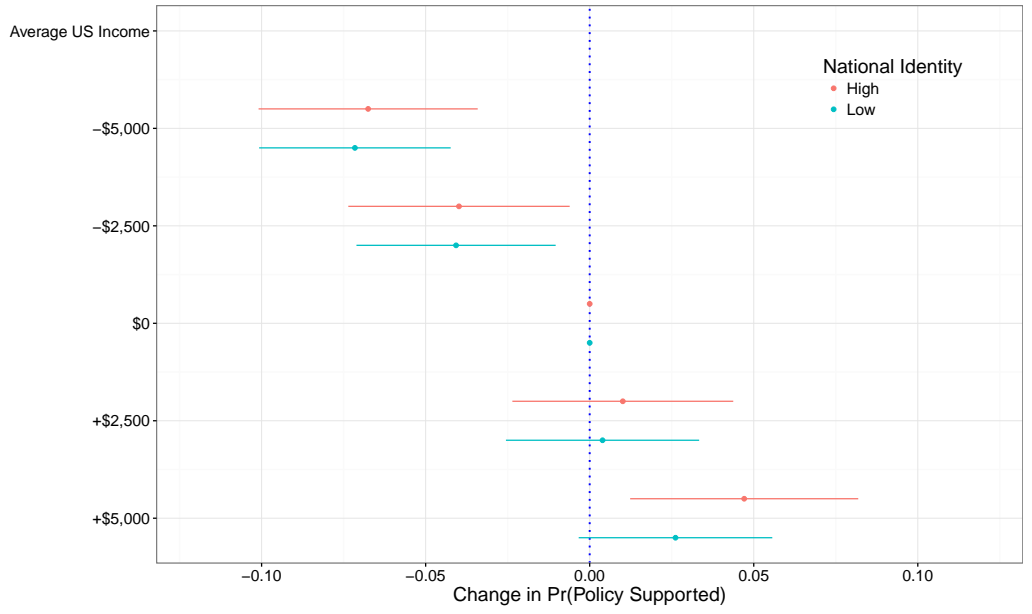




\section{Average income changes affect individuals identifying with both parties very similarly.}

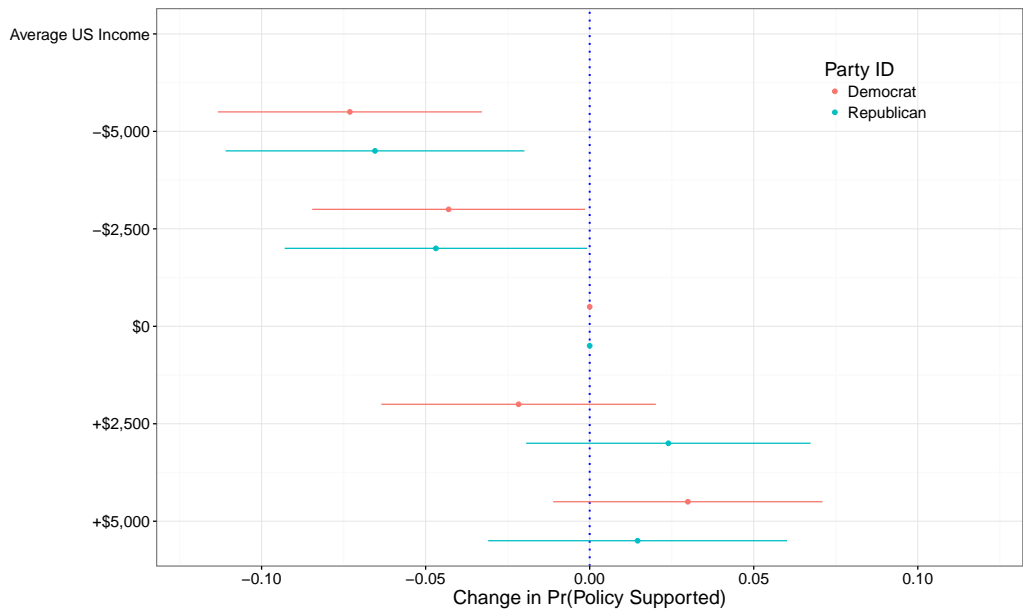




\section{Altruism helps to explain how average income increases influence support for policy.}

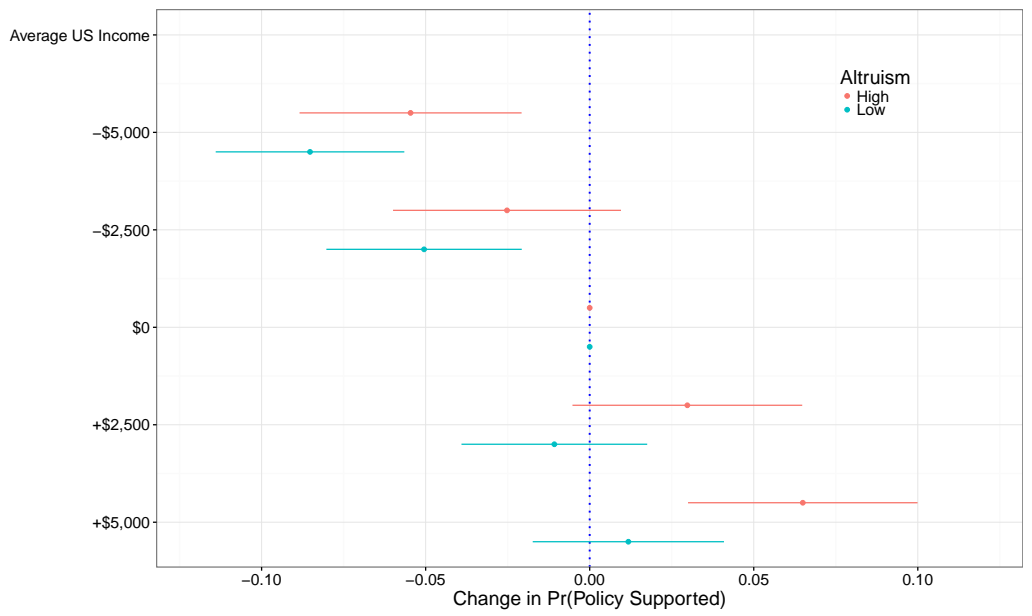




\section{Reciprocity helps to explain how average income increases influence support for policy.}

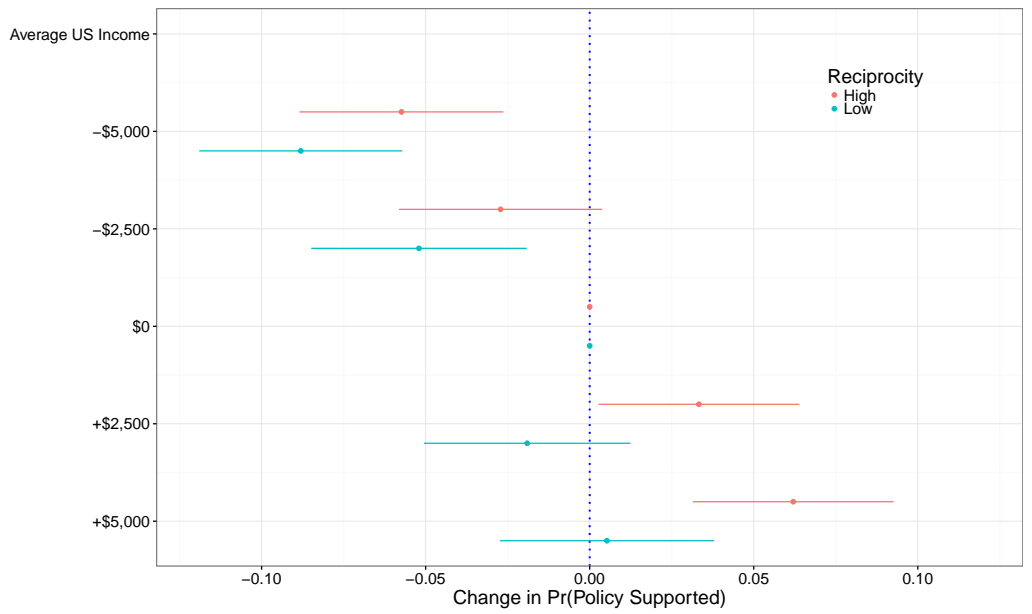




\section{Using relative instead of absolute income changes leads to similar results.}

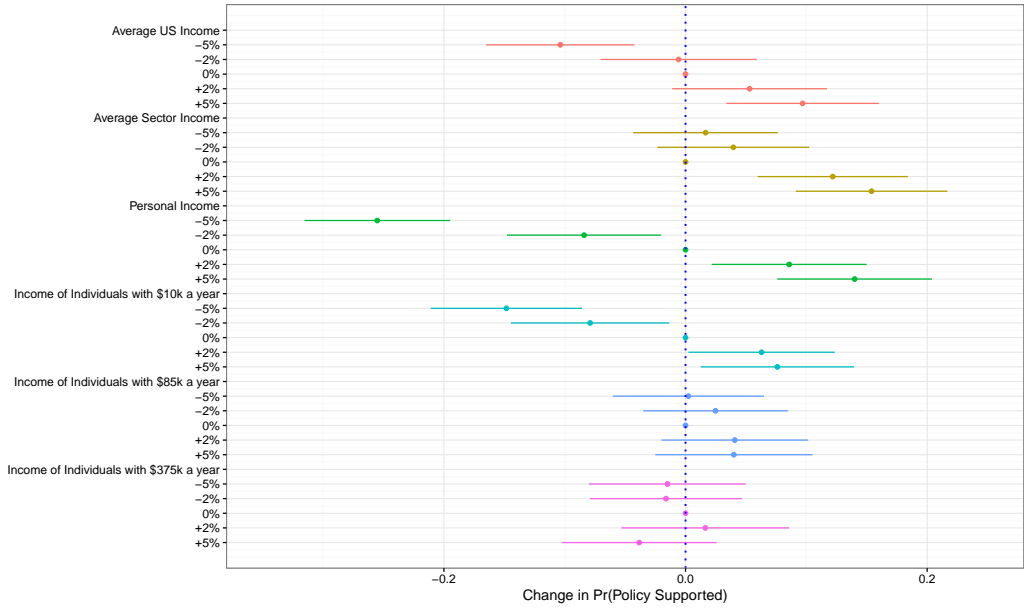

